Original article

\title{
Association of sleep disorder with academic performance among medical students in Sudan
}

\author{
Mubashir Zafar, Eltigani O.M. Omer, Mohamed Elfatih Hassan, Khalid A. Ansari \\ Imam Abdulrahman Bin Faisal University, Dammam, Kingdom of Saudi Arabia
}

Received 20 May 2019, Revised 22 February 2020, Accepted 24 April 2020

(C) 2019, Zafar M., Omer E.O.M., Hassan M.E., Ansari K.

(C) 2019, Russian Open Medical Journal

Abstract: Background - Sleep disorder is a common problem amongst medical students. The objective of this study is to determine the association of sleep disorder with academic performances among medical students in Sudan.

Methods - A cross-sectional study was conducted in which 199 medical students were selected through simple random sampling techniques. Pittsburgh Sleep Quality Index and Epworth Sleepiness Scale were used to assess the sleep pattern and daytime sleepiness respectively. Logistic regression analysis was used to determine the association of sleep disorder with academic performance.

Results - Majority of the students (82.5\%) suffered poor sleep quality and $56.5 \%$ were suffered from severe day time sleepiness. All the characteristics of sleep quality were associated with poor academic performance but only sleep duration [OR 1.05(CI 1.01-2.02)], use of sleep medication [OR 14.99(Cl 1.46-20.32)], global PSQI score [OR 2.86(Cl 1.51-15.90)] and day time sleepiness [OR 4.80(Cl 1.21-35.41)] were a statistically significant association with poor academic performance.

Conclusion - A high prevalence of sleep disorder and its associated with poor academic performance was found in medical students. There is a need for a formulation of policies to address the factors which affect sleep of students.

Keywords: academic, disorder, sleep, students.

Cite as Zafar M, Omer EOM, Hassan ME, Ansari K. Association of sleep disorder with academic performance among medical students in Sudan. Russian Open Medical Journal 2020; 9: e0208.

Correspondence to Mubashir Zafar, E-mail: mzzahmed@iau.edu.sa.

\section{Introduction}

Sleep is an important physiological process for good physical and mental health of a human being ${ }^{1}$. It affects the quality of life because it is the physiological need for every human. Normal, average sleep in humans is approximately 8 hours and it varies between other living things [1-3]. Sleep is important for the ability to learn because it refreshes the memory of human beings $[4,5]$. Professional students have experienced sleep problems due to a burden of study [6].

Undergraduate students have suffered sleep disorders compared to the general population because of study and work stress [7]. Another study found that an average of fifty percent of students suffered day time sleepiness which leads to poor academic performance and increased risk for psychological problems [8].

There are different studies which found that sleep disorders associated with poor academic performance such as reduced sleep quality, later bedtimes and day time sleepiness tended to affect students' academic performance and reduced mental cognitive ability [8-9].

The previous study found that sleep disorder had significant effects in psychomotor abilities of students such as decreased focus on lecture attention after 15 hours of awaking on reaction times [10]. There are different aspects in the life of undergraduate students which is a typical group as studies are more demanding in terms of course content as well as working hours [9]. Medical students work for long hours daily; it is a risk for patient safety during training of medical students [10]. It has been reported that sleep quality affects undergraduate students' physical and mental health, and consequently their working capacity [11].

Poor sleep quality among undergraduates not only leads to physical and psychological morbidities, but also affects learning, memory and cognition [12]. A study was conducted in a Nigerian university which showed that $32.5 \%$ of medical students were sleepdeprived [13]. Similarly, a study conducted in a medical college showed that a poor sleep habit was common among medical students and was associated with lifestyle [14].

Globally, medical students are more susceptible to sleep disturbance and problems. In previous studies conducted in China found that only a few $(19 \%)$ of medical students suffered poor sleep, this difference was found in different academic years [10]. Another study was conducted in India. It displayed the idea that $30.6 \%$ of medical students were reported daytime sleepiness but females were affected less [15].

According to the International Classification of Sleep Disorders (DCSC, 2001), most of the undergraduate students were under this classification of sleep disorder such as daytime sleepiness, decreased sleep duration, sleep by medication, sleep latency therefore it is assumed that their sleep disorders lead to bad academic performances [16].

Medical students around the globe have sleep problems and are more prone to develop insomnia and narcolepsy [14]. There is 
little awareness among medical students about sleep disorders. Teachers of medical colleges have a lack of skills to identify the sleep disorder in the students which lead to poor academic performance. They are also not very well informed about the sleep patterns and only a small percentage of students were aware that sleep disorders could be linked to diabetes, anemia, metabolic syndrome, and attention deficit disorder. But sleep problems were considered as a significant clinical issue by $93 \%$ of the students, and they believed that people with sleep disorders should seek treatment [17].

In Sudan, a total 40 medical colleges and around 2500 students were enrolled every year and in the best of our knowledge, no previous study was conducted to determine the relationship of sleep pattern and disorder with academic performance among medical students in Sudan. The results of this study will help both students and medical college managements to formulate the policy which will further improve the performance of medical students. This study was conducted for the purpose of evaluating sleep patterns and habits of undergraduate medical and academic performance association in Sudan.

Table 1. Socio-demographic characteristics of study participants ( $\mathrm{n}=199)$

\begin{tabular}{|c|c|c|}
\hline Sr. No & Characteristics & Frequency (\%) \\
\hline 1. & Age, years & $21.12 \pm 1.52$ \\
\hline \multirow[t]{3}{*}{2.} & Gender & \\
\hline & Male & $73(36.7)$ \\
\hline & Female & $126(63.3)$ \\
\hline \multirow[t]{3}{*}{3.} & Marital Status & \\
\hline & Single & $191(96)$ \\
\hline & Married & $8(4)$ \\
\hline \multirow[t]{6}{*}{4.} & Academic Year of Study & \\
\hline & First year & $10(5)$ \\
\hline & Second year & $26(13.1)$ \\
\hline & Third Year & 35 (17.6) \\
\hline & Fourth Year & 75 (37.7) \\
\hline & Final Year & $53(26.6)$ \\
\hline \multirow[t]{3}{*}{5.} & Father Occupation & \\
\hline & Business & $57(28.6)$ \\
\hline & Job & $142(71.4)$ \\
\hline \multirow[t]{3}{*}{6} & Smoking & \\
\hline & Ever & $15(7.5)$ \\
\hline & Never & $184(92.5)$ \\
\hline \multirow[t]{3}{*}{7.} & Family History of Sleep Disorder & \\
\hline & Yes & $70(35.2)$ \\
\hline & No & $129(64.8)$ \\
\hline \multirow[t]{4}{*}{8.} & Academic Score (GPA)* (Last Semester) & \\
\hline & Low & $155(77)$ \\
\hline & Average & $29(15)$ \\
\hline & Good & $16(8)$ \\
\hline
\end{tabular}

Continuous variables presented as mean with standard deviation $-\mathrm{M} \pm \mathrm{SD}$. Binary variables presented as frequencies and percentages $-n(\%)$.

Table 2 Prevalence of sleep disorder among study participants $(\mathrm{n}=199)$

\begin{tabular}{llcc}
\hline S. No & \multicolumn{1}{c}{ Characteristics } & Frequency $(n)$ & Proportion (\%) \\
\hline 1 & Normal Sleep* & 35 & 17.5 \\
2 & Abnormal Sleep* & 165 & 82.5 \\
3 & No Day Time Sleep*** & 5 & 2.5 \\
4 & Mild day time*** Sleepiness & 63 & 31.5 \\
5 & Moderate day time*** Sleepiness & 19 & 9.5 \\
6 & Sever Day time*** Sleepiness & 113 & 56.5 \\
\hline
\end{tabular}

* PSQI scale $\left(1-10=\right.$ Normal, $>10=$ Abnormal), ${ }^{* * *}$ Epworth sleepiness scale $(0-7=$ normal, $8-9=$ mild, $10-15=$ moderate, $16-24=$ Severe day time).

\section{Material and Methods}

\section{Operational definitions}

Sleep Habits - Sleep habits are determined by the PSQI (Pittsburgh Sleep Quality Index to assess the sleep pattern) scale which is a validated scale. PSQI score of $0-4$ suggests "Good" and 5 or greater indicates "Poor" habit

Day time Sleepiness - It determined by a validated scale called ESS (Epworth Sleepiness Scale to measure daytime sleepiness). Day dozing is lower than normal if the ESS score is 0-5, higher than normal if the ESS score is 5-9, Mild if the ESS score is 10-12, Moderate if the ESS score is $13-15$ and Severe if the ESS score is $>16$.

Academic Score grade - means CGPA score in a semester. It is classified into good, average and poor. Good is above 4.5, Average from 2.5-4.5 and poor is below 2.5.

\section{Study design and study site}

It's a cross sectional study conducted at different Medical Colleges of Sudan.

\section{Sample size}

Sample size was calculated by WHO which is a sample size calculator by keeping the proportions of sleep disorder 15\% [18], using a $95 \%$ confidence interval and $5 \%$ margin of error. The total sample size was 199 subjects in the study. Multistage systematic random sampling was used to select the study participants.

\section{Inclusion criteria and exclusion criteria}

Participants were included all academic year of undergraduate students of medical colleges and those who were willing to giving consent were included. Participants excluded were All DayScholars students of medical college

\section{Study variables}

Independent variables are age, gender, academic year, hostelite/day-scholar, sleep hours, narcolepsy by Epworth Sleepiness Scale (ESS), sleep habits by Pittsburgh Sleep Quality Index (PSQI), sleep habits during exams, sleep habits and extracurricular activities, stress and sleep habits, sleep and physical activity, satisfaction with sleep habits, academic grades. GPA of students was the dependent variables.

\section{Study tool}

Measurement Tool - Sleep disorder is measured by a structured questionnaire which is based on the objective of the study. It consists of two sections which is socio-demographic characteristic and sleep disorder of participants. The Performa contains validated Standard sleep scales i.e. Epworth Sleepiness Scale (ESS) and Pittsburgh Sleep Quality Index (PSQI). Subjects were given instructions prior to data collection. Both scales were used in the Arabic version and validated [19].

Scoring - PSQI scale is a validated scale. If PSQI score is 0-4 then "Good" sleep habit and if 5 or greater than 5 then "Poor" sleep habit. 
Table 3. Association of academic score with sleep quality and day time sleepiness

\begin{tabular}{|c|c|c|c|}
\hline S. No & Characteristics & Poor Academic score* Crude Odd Ratio (95\% CI) & Poor Academic Score* (Adjusted Odd Ratio 95\% Cl) \\
\hline \multirow[t]{4}{*}{1} & Subjective Sleep Quality & & \\
\hline & Mild Sleepiness & 1 & 1 \\
\hline & Moderate Sleepiness & $1.02(0.22-4.53)$ & $1.09(0.32-4.83)$ \\
\hline & Sever Sleepiness & $0.83(0.24-2.80)$ & $1.74(0.42-7.07)$ \\
\hline \multirow[t]{4}{*}{2} & Sleep Latency & & \\
\hline & $16-30$ minutes & 1 & 1 \\
\hline & $31-60$ minutes & $1.23(0.30-4.98)$ & $2.05(0.53-7.94)$ \\
\hline & $>60$ minutes & $1.15(0.20-1.85)$ & $2.19(0.61-7.81)$ \\
\hline \multirow[t]{4}{*}{3} & Sleep Duration & & \\
\hline & $6-7$ hours & 1 & 1 \\
\hline & $5-6$ hours & $1.60(0.44-5.77)$ & $1.15(1.02-2.21)$ \\
\hline & $<5$ hours & $1.18(0.29-4.79)$ & $1.05(1.01-2.02)$ \\
\hline \multirow[t]{4}{*}{4} & Habitual Sleep Efficiency ( \%) & & \\
\hline & $75-84$ & 1 & 1 \\
\hline & $65-74$ & $1.86(0.61-5.71)$ & $1.26(0.32-4.93)$ \\
\hline & $<65$ & $1.44(0.41-4.99)$ & $1.63(0.36-7.30)$ \\
\hline \multirow[t]{4}{*}{5} & Sleep Disturbance & & \\
\hline & Less than once the week & 1 & 1 \\
\hline & once or twice the week & $4.62(0.27-17.65)$ & $6.65(0.29-15.25)$ \\
\hline & more than twice the week & $5.10(0.29-18.63)$ & $11.49(0.46-17.31)$ \\
\hline \multirow[t]{4}{*}{6} & Use of Sleep Medication & & \\
\hline & less than once the week & 1 & 7 \\
\hline & Once or twice the week & $6.23(0.87-30.87)$ & $14.99(1.46-20.32)$ \\
\hline & more than twice the week & $8.00(2.24-28.55)$ & $2.53(0.41-15.43)$ \\
\hline \multirow[t]{4}{*}{7} & Day time Dysfunction & & \\
\hline & Only very slight problem & 1 & 1 \\
\hline & somewhat a problem & $1.87(0.40-8.61)$ & $1.50(0.98-5.61)$ \\
\hline & a very big problem & $4.33(0.95-19.60)$ & $2.33(1.01-12.21)$ \\
\hline \multirow[t]{3}{*}{8} & Global PSQI** scale & & \\
\hline & Normal Sleep & 1 & 1 \\
\hline & Poor Sleep & $3.59(1.20-10.72)$ & $2.86(1.51-15.90)$ \\
\hline \multirow[t]{4}{*}{9} & Narcolepsy (Day Time Sleepine & & \\
\hline & Mild Day time Sleepiness & 1 & 1 \\
\hline & Moderate Day Time Sleepless & $7.00(1.45-33.69)$ & $4.80(1.21-35.41)$ \\
\hline & Severe Day Time Sleepiness & $3.75(0.63-22.04)$ & $2.88(0.25-32.40)$ \\
\hline
\end{tabular}

*Academic Score Poor 0-3, Good>3; ** Pittsburg Sleep Quality index

Table 4 Association of Socio-Demographic Characteristics with Sleep Quality

\begin{tabular}{|c|c|c|c|}
\hline Sr. No & Characteristics & Poor Sleep Quality Crude Odd Ratio (95\% CI) & Poor Sleep Quality Adjusted Odd Ration (95\% CI) \\
\hline 1. & Age, years, mean $\pm S D$ & $21.12 \pm 1.52$ & \\
\hline \multirow[t]{3}{*}{2} & Gender & & \\
\hline & Female & 1 & 1 \\
\hline & Male & $1.86(0.94-3.67)$ & $1.03(0.23-4.58)$ \\
\hline \multirow[t]{3}{*}{3} & Marital Status & & \\
\hline & Single & 1 & 1 \\
\hline & Married & $1.18(0.23--6.04)$ & $1.72(0.56-5.24)$ \\
\hline \multirow[t]{6}{*}{4} & Academic Year & & \\
\hline & First & 1 & 1 \\
\hline & Second & $3.69(1.18-11.46)$ & $4.10(1.28-13.09)$ \\
\hline & Third & $1.47(0.56-3.87)$ & $1.52(0.56-4.11)$ \\
\hline & Fourth & $2.54(0.90-7.17)$ & $3.10(0.98-9.80)$ \\
\hline & Final & $1.16(0.49-2.70)$ & $1.27(0.52-3.11)$ \\
\hline \multirow[t]{3}{*}{5} & Father Occupation & & \\
\hline & Business & 1 & 1 \\
\hline & Job & $1.99(1.03-3.85)$ & $2.44(1.18-5.01)$ \\
\hline \multirow[t]{3}{*}{6} & Smoking & & \\
\hline & Never & 1 & 1 \\
\hline & Ever & $1.61(1.23-5.96)$ & $1.03(0.23-4.58)$ \\
\hline
\end{tabular}


Table 5 Association of socio-demographic characteristics with day time sleep

\begin{tabular}{|c|c|c|c|}
\hline Sr.No & Characteristics & Day time Sleepiness (Crude Odd Ratio 95\% Cl) & Day Time Sleepiness (Adjusted Odd Ratio 95\% Cl) \\
\hline 1. & Age (Mean \pm SD) & $21.12 \pm 1.52$ & \\
\hline \multirow[t]{3}{*}{2} & Gender & & \\
\hline & Female & 1 & 1 \\
\hline & Male & $1.10(0.61-1.96)$ & $0.97(0.53-1.79)$ \\
\hline \multirow[t]{3}{*}{3} & Marital Status & & \\
\hline & Single & 1 & 1 \\
\hline & Married & $4.23(1.54-11.66)$ & $3.74(1.33-10.67)$ \\
\hline \multirow[t]{6}{*}{4} & Academic Year & & \\
\hline & First & 1 & 1 \\
\hline & Second & $0.37(0.14-0.94)$ & $0.36(0.14-0.95)$ \\
\hline & Third & $0.56(0.22-1.42)$ & $0.55(0.21-1.43)$ \\
\hline & Fourth & $0.55(0.22-1.39)$ & $0.28(0.10-0.82)$ \\
\hline & Final & $0.84(0.35-1.98)$ & $0.76(0.32-1.84)$ \\
\hline \multirow[t]{3}{*}{5} & Father Occupation & & \\
\hline & Business & 1 & 1 \\
\hline & Job & $1.00(0.54-1.87)$ & $1.12(0.58-2.13)$ \\
\hline \multirow[t]{3}{*}{6} & Smoking & & \\
\hline & Never & 1 & 1 \\
\hline & Ever & $3.36(1.01-12.30)$ & $2.47(0.62-10.09)$ \\
\hline
\end{tabular}

ESS is a verified scale used for determining the Narcolepsy, Day dozing is lower than normal, if the ESS score is 0-5, and it is higher than Normal. If the ESS score is 5-9, it is a Mild Narcolepsy. If the ESS score is 10-12, it is a Moderate Narcolepsy. If the ESS score is 13-15 Severe Narcolepsy is if the ESS score is above 16 it is very severe.

Data collection method - Permission was taken from participants and participants were informed about the purpose of the study. Written Consent was obtained before asking questions from the participants.

Data Analysis Procedure - Data was analyzed by using SPSS version 22. Data from the questionnaire was encoded into the database by a data encoder. Questionnaire forms and databases were checked for completeness daily. Data was entered twice and then cleaned for any missing variables. All the data was supervised by a principal investigator on a regular basis. In terms of quantitative variables like age, family size, total household income, the Descriptive Analysis was calculated and for skewed data, the median and inter-quartile ranges (IQR) were reported. Categorical variables like gender, years of education and occupation were described by using frequencies and percentages. Association between the sleep disorders with academic performance was determined by logistic regression analysis. Independent variables which appeared with a $\mathrm{p}$-value $\leq 0.05$ were included in the multivariate analysis. Age, gender and academic year were adjusted in the multivariate analysis.

\section{Results}

\section{Socio-Demographic Characteristic of Study Participants}

Mean age of study participants was 21.2 years with an SD of 1.52. Most of them were females (63.3\%), only $7.5 \%$ were smokers; the majorities were poor grades in the semester exam (77\%). Majority (71.4\%) of father occupation was white collar (office job), $35.2 \%$ was family history of sleep disorder (Table 1 ).

\section{Prevalence of Sleep Disorder among study participants}

Most (82.5\%) of the students has sleep disorder and majority (56.5\%) has daytime of sleepiness disorder (Table 2 ).

\section{Association of Sleep Disorder with Academic Performance}

All the characteristics of sleep quality were associated with poor academic performance but only sleep duration [OR $1.05(\mathrm{Cl}$ 1.01-2.02)], use of sleep medication [OR 14.99 (Cl 1.46-20.32)], global PSQI score [OR $2.86(\mathrm{Cl} 1.51-15.90)]$ and day time sleepiness [OR $4.80(\mathrm{Cl} 1.21-35.41)]$ were statistically a significant association with poor academic performance. (Table 3)

\section{Association of Socio-Demographic characteristics with Sleep} quality

All the characteristics of socio-demographic were associated with poor sleep quality but only the second academic year [OR $4.10(\mathrm{Cl} 1.28-13.09$ ) and father occupation of office job [OR 2.44(Cl 1.18-5.01) were statistically significant factors associated with poor sleep quality. (Table 4)

\section{Association of Socio-Demographic characteristics with} daytime sleepiness

All the characteristics of socio-demographic were associated with daytime sleepiness, but only a marital status of married [OR $3.74(\mathrm{Cl} 1.33-10.67)]$ was statistically significant associated with daytime sleepiness. (Table 5 )

\section{Discussion}

This study shows that a high prevalence of sleep disorder and daytime sleepiness among most of the medical students affected their academic performance in their study. These study results were consistent with other studies' results [19-21]. This result explained that the majority of sleep disorder associated with academic performance is due to a lack of sleep in weekend. A result of this study was consistent with other study which was conducted in USA [22]. In the result of previous studies, it is confirmed that sleep plays an important role on mental competency among students [23-25].

In the study there is a significant association of daytime sleepiness with academic performance which is homogenous with other study results [26]. This study shows that $39.5 \%$ of medical 
students performed bad in the semester exam because of a daytime sleepiness problem. Another study which was conducted in Korea, showed that a strong presence of poor sleep quality with daytime sleepiness is associated with a decrease in academic performance [27].

In this study, it showed that academic performance decreased as the academic year increased from the $1^{\text {st }}$ year to the final year due to sleep disturbance because study burden increases as the academic year goes from preclinical to clinical year. This result is unvarying with the previous studies [28-30].

This study also revealed that father occupation affected the sleep disorder of students. Stress in the job affected the environment of family living, whole family including student have sleep disorder due to stress in the job this result was contrast of other study results [32-34] because of our study sample majority of fathers occupation is job compare to business.

Academic performance is also affected indirectly by smoking, because those students who smoke cigarettes due to sleep disorder affect their academic performance. A recent study which was conducted in the USA [35], revealed that the students who smoked lead to lose up to 2 hours of sleep per night, this led to a decrease in sleep duration and ultimately their academic performance was decreased.

The important strength of this study is that sample size which is truly representative of the population of Sudan medical students, covers major medical colleges all over the country. Second strength is that it addresses the confounder in the study results and excludes variables which have an interaction and affect results. This study has some limitations such as it's a cross sectional study which cannot be determined in the temporal causation and its self-reported information which may be biased in the reporting.

\section{Conclusion}

Study findings showed that sleep disorder was more prevalent among students and it is associated with academic performance. This study recommends making a policy and tool formation like curriculum revision and counseling to students for reducing the sleep disorder and increases their performance academically.

\section{Ethical considerations}

The study was approved from the Institutional review board of the medical college of Sudan. Verbal and written informed consents were taken from the study participants.

\section{Funding}

This is a self-funded project.

\section{Authors Contribution}

$\mathrm{MZ}$ the correspondence author conceived the concept and design, data interpretation. He drafted the manuscript and revised the article. EMO substantial contribution in the data collection, EM and KA contributed in proof reading.

\section{Acknowledgement}

We thank all teachers and students who help in this research.

\section{Conflict of Interest}

There is no conflict of interest between authors.

\section{References}

1. Borbély AA, Daan S, Wirz-Justice A, Deboer T. The two-process model of sleep regulation: a reappraisal. J Sleep Res 2016; 25(2): 131-143. https://doi.org/10.1111/jsr.12371.

2. Manzar MD, Zannat W, Hussain ME, Pandi-Perumal SR, Bahammam AS, Barakat D, et al. Dimensionality of the Pittsburgh Sleep Quality Index in the young collegiate adults. Springerplus 2016; 5(1): 1550. https://doi.org/10.1186/s40064-016-3234-x.

3. Colten HR, Altevogt BM, Institute of Medicine (US) Committee on Sleep Medicine and Research, eds. Sleep disorders and sleep deprivation: An unmet public health problem. Handbook of Sleep Research. Washington, DC: National Academies Press (US). 2006: 424 p. https://doi.org/10.17226/11617.

4. Ezquiaga AD, Vas CP, Neito GP, Blanco SA, Schweimer M, Roca L, et al Sleep quality evaluation in medical students. J Neurol Sci 2015 357(Supp 1): e435. http://doi.org/10.1016/j.jns.2015.09.063.

5. Demos KE, Hart CN, Sweet LH, Mailloux KA, Trautvetter J, Williams SE, et al. Partial sleep deprivation impacts impulsive action but not impulsive decision-making. Physiol Behav 2016; 164 (Pt A): 214-219. https://doi.org/10.1016/j.physbeh.2016.06.003.

6. Spanò G, Gómez RL, Demara BI, Alt M, Cowen SL, Edgin JO. REM sleep in naps differentially relates to memory consolidation in typical preschoolers and children with Down syndrome. Proc Natl Acad Sci U S A 2018; 115(46): $11844-11849$. https://doi.org/10.1073/pnas.1811488115.

7. Murray JM, Sletten TL, Magee M, Gordon C, Lovato N, Bartlett DJ, et al. Prevalence of circadian misalignment and its association with depressive symptoms in delayed sleep phase disorder. Sleep 2017; 40(1): 10.1093/sleep/zsw002. https://doi.org/10.1093/sleep/zsw002.

8. Mirghani HO, Ahmed MA, Elbadawi AS. Daytime sleepiness and chronic sleep deprivation effects on academic performance among the Sudanese medical students. J Taibah Univ Med Sci 2015; 10(4): 467 470. https://doi.org/10.1016/j.jtumed.2015.05.003.

9. Mirghani HO, Mohammed OS, Almurtadha YM, Ahmed MS. Good sleep quality is associated with better academic performance among Sudanese medical students. BMC Res Notes 2015; 8: 706. https://doi.org/10.1186/s13104-015-1712-9.

10. Wheaton AG, Chapman DP, Croft JB. School start times, sleep, behavioral, health, and academic outcomes: a review of the literature. J Sch Health 2016; 86(5): 363-381. https://doi.org/10.1111/josh.12388.

11. Subhaprada SC, Vijayakumari S, Rajasekhar T, Venkateswarlu U. An interventional study on sleep hygiene among medical students. Int $J$ Community Med Public Health 2017; 4(2): 352-356. http://doi.org/10.18203/2394-6040.ijcmph20170254.

12. Siddiqui AF, Al-Musa H, Al-Amri H, Al-Qahtani A, Al-Shahrani M, AlQahtani M. Sleep patterns and predictors of poor sleep quality among medical students in King Khalid University, Saudi Arabia. Malays J Med Sci 2016; 23(6): 94-102. https://doi.org/10.21315/mjms2016.23.6.10.

13. Almojali Al, Almalki SA, Alothman AS, Masuadi EM, Alaqeel MK. The prevalence and association of stress with sleep quality among medical students. J Epidemiol Glob Health 2017; 7(3): 169-174. https://doi.org/10.1016/j.jegh.2017.04.005.

14. Ogunsemi OO, Afe TO, Deji-Agboola MA, Osalusi BS, Adeleye O, Ale A, et al. Quality of sleep and psychological morbidity among paramedical and medical students in Southwest Nigeria. Res J of Health Sci 2018; 6(2): 63-71. https://doi.org/10.4314/rejhs.v6i2.3.

15. Adams RJ, Appleton SL, Taylor AW, Gill TK, Lang C, McEvoy RD, et al. Sleep health of Australian adults in 2016: results of the 2016 Sleep Health Foundation national survey. Sleep Health 2017; 3(1): 35-42. https://doi.org/10.1016/j.sleh.2016.11.005.

16. Gomes AA, Tavares J, Azevedo, MH. Sleep-wake patterns and academic performance in university students. Paper presented at the European Conference on Educational Research, University of Lisbon, 11-14 September 2002. Education-Line [electronic database] http://www.leeds.ac.uk/educol/documents/00002200.html. 
17. American Academy of Sleep Medicine. International classification of sleep disorders, revised: Diagnostic and coding manual. Chicago, Illinois: American Academy of Sleep Medicine, 2001: 399 p. https://vct.iums.ac.ir/uploads/icsd.pdf.

18. Azad MC, Fraser K, Rumana N, Abdullah AF, Shahana N, Hanly PJ, et al. Sleep disturbances among medical students: a global perspective. J Clin Sleep Med 2015; 11(1): 69-74. https://doi.org/10.5664/jcsm.4370.

19. Ahmed AE, Fatani A, Al-Harbi A, Al-Shimemeri A, Ali YZ, Baharoon S, et al. Validation of the Arabic version of the Epworth Sleepiness Scale. J Epidemiol Glob Health 2014; 4(4): 297-302. https://doi.org/10.1016/j.jegh.2014.04.004.

20. Lumley S, Ward P, Roberts L, Mann JP. Self-Reported Extracurricular Activity, Academic Success, and Quality of Life in UK Medical Students. Int J Med Educ 2015; 6: 111-117. https://doi.org/10.5116/ijme.55f8.5f04.

21. Rajendran D, Vinod PB, Karthika M, Prathibha MT. Excessive daytime sleepiness in medical students. J Evolution Med Dent Sci 2018; 7(6): 747-750. https://doi.org/10.14260/jemds/2018/169.

22. Sakamoto N, Gozal D, Smith DL, Yang L, Morimoto N, Wada H, et al. Sleep duration, snoring prevalence, obesity, and behavioral problems in a large cohort of primary school students in Japan. Sleep 2017; 40(3). https://doi.org/10.1093/sleep/zsw082

23. Ludwig B, Smith SS, Heussler H. Exploring the association between perceived excessive daytime sleepiness in children and academic outcomes. Issues in Educational Research 2019; 29(3): 841-857. http://www.iier.org.au/iier29/ludwig.pdf.

24. Becker SP, Langberg JM, Eadeh HM, Isaacson PA, Bourchtein E. Sleep and daytime sleepiness in adolescents with and without ADHD: differences across ratings, daily diary, and actigraphy. J Child Psychol Psychiatry 2019; 60(9): 1021-1031. https://doi.org/10.1111/jcpp.13061.

25. Short MA, Kuula L, Gradisar M, Pesonen AK. How internal and external cues for bedtime affect sleep and adaptive functioning in adolescents. Sleep Med 2019; 59: 1-6. https://doi.org/10.1016/j.sleep.2018.11.018.

26. Tachibana M, Kato T, Kato-Nishimura K, Matsuzawa S, Mohri I, Taniike M. Associations of sleep bruxism with age, sleep apnea, and daytime problematic behaviors in children. Oral Dis 2016; 22(6): 557-565. https://doi.org/10.1111/odi.12492.

27. Noack H, Schick W, Mallot H, Born J. Sleep enhances knowledge of routes and regions in spatial environments. Learn Mem 2017; 24(3): 140-144. https://doi.org/10.1101//m.043984.116.

28. Csábi E, Benedek P, Janacsek K, Zavecz Z, Katona G, Nemeth D. Declarative and non-declarative memory consolidation in children with sleep disorder. Front Hum Neurosci 2016; 9: 709. https://doi.org/10.3389/fnhum.2015.00709.

29. Khan HI, Arshad A, Ramzan M, Irshad MR, Furqan A. Effect of Sleep Pattern on Academic Performance of Medical Students. Ophthalmology Update 2018; 16(2): 691-694. https://www.ophthalmologyupdate.com/issue-archive/Apr-Jun2018/18.

30. Shimura A, Hideo $S$, Takaesu $Y$, Nomura $R$, Komada $Y$, Inoue $T$. Comprehensive assessment of the impact of life habits on sleep disturbance, chronotype, and daytime sleepiness among high-school students. Sleep Med 2018; 44: 12-18. https://doi.org/10.1016/j.sleep.2017.10.011.

31. Taylor AK, Netsi E, O'Mahen H, Stein A, Evans J, Pearson RM. The association between maternal postnatal depressive symptoms and offspring sleep problems in adolescence. Psychol Med 2017; 47(3): 451-459. https://doi.org/10.1017/s0033291716002427.

32. Berger RH, Diaz A, Valiente C, Eisenberg N, Spinrad TL, Thompson MS, et al. Sleep duration moderates the association between children's temperament and academic achievement. Early Educ Dev 2018; 29(5): 624-640. https://doi.org/10.1080/10409289.2017.1404884.

33. Chen WL, Chen JH. Sleep deprivation and the development of leadership and need for cognition during the college years. J Adolesc 2019; 73: 95-99. https://doi.org/10.1016/j.adolescence.2019.04.003.
34. Prehn-Kristensen A, Böhmig A, Schult J, Pedersen A, Wiesner CD, Baving L. Does sleep help prevent forgetting rewarded memory representations in children and adults? Front Psychol 2018; 9: 924. https://doi.org/10.3389/fpsyg.2018.00924.

35. Prayag AS, Najjar RP, Gronfier C. Melatonin suppression is exquisitely sensitive to light and primarily driven by melanopsin in humans. $J$ Pineal Res 2019; 66(4): e12562. https://doi.org/10.1111/jpi.12562.

\section{Authors:}

Mubashir Zafar - FCPS, Assistant Professor, Department of Public Health, College of Public Health, Imamm Abdul Rahman Bin Faisal university, Dammam, Saudi Arabia. https://orcid.org/0000-0002-7440-0635.

Eltigani Osman Musa Omer - Phd, Assistant Professor, Department of Public Health, College of Public Health, Imamm Abdul Rahman Bin Faisal university, Dammam, Saudi Arabia. https://orcid.org/0000-0003-2320 4850.

Mohamed Elfatih Hassan - Phd, Assistant Professor, Department of Public Health, College of Public Health, Imamm Abdul Rahman Bin Faisal university, Dammam, Saudi Arabia.

Khalid Ansari - Phd, Associate Professor, Respiratory Therapy department, College of Applied Medical Sciences, Imamm Abdul Rahman Bin Faisal university, Dammam, Saudi Arabia. https://orcid.org-0000-0002-4241$\underline{6333}$. 